\title{
Pregnancy termination rates after fetal diagnosis of single ventricle: A 17-year retrospective review
}

\author{
Mowers KL ${ }^{1,2 *}$, Buzzard $\mathrm{CJ}^{2}$, and Kavey REW ${ }^{2}$ \\ ${ }^{1}$ Division of Pediatric Cardiology, Department of Pediatrics, Saint Louis Children's Hospital, Washington University School of Medicine, Saint Louis, MO, USA \\ ${ }^{2}$ Division of Pediatric Cardiology, Department of Pediatrics, Golisano Children's Hospital, University of Rochester, Rochester, NY, USA
}

\begin{abstract}
Background: Contemporary reports of termination rates after Fetal Echocardiographic (FE) diagnosis of congenital heart disease are limited and none have reported temporal trends. Progressive improvements in surgical outcomes were hypothesized to impact termination rates when the diagnosis of hypoplastic left heart syndrome(HLHS)/Single Ventricle (SV) is made early in fetal life.

Methods: We reviewed all fetal echocardiograms performed in a tertiary center pediatric cardiology program between 5/1996 and 1/2013. FE interpretation and all related counseling were performed by a single cardiologist. Annual termination rates were determined and maternal demographics and other identified fetal abnormalities were compared between continued and terminated pregnancies. Review of the medical literature for fetal ultrasound and HLHS/ single ventricle was performed to provide historic comparison of pregnancy termination rates.

Results: 2411 FEs were performed with 149 diagnoses of SV (.062\%). In 31 cases (21\%), the FE diagnosis was made at > 24 weeks' gestation and these cases are not included in the analysis. Of the remaining 118 cases, $48 \%$ were diagnosed with HLHS, 21\% hypoplastic right heart, 19\% complex single ventricle, and 12\% unbalanced atrioventricular septal defect. Overall termination rate was $15.4 \%$, with $95 \%$ CI (11.67\%-20.53\%). Termination rates varied from year to year throughout the review period but there was no significant trend over time. There was no statistically significant difference in maternal demographics (age, marital status, ethnicity, gestational age at diagnosis) between continued pregnancies and those which were terminated. Termination rates did not differ when fetal chromosomal abnormalities or high risk cardiac characteristics (severe AV valve insufficiency, intact atrial septum, ventricular dysfunction) were identified.

Conclusions: Over a 17-year period in our center, termination rates in pregnancies with FE diagnosis of SV were consistently low, comparable with previous reports from American centers over the last 20 years. Despite major improvements in cardiac surgical outcomes over this time period, there was no significant trend in termination rates over time. This lack of change suggests that factors other than cardiac prognosis are major determinants in family decision-making after a fetal diagnosis of SV. A significantly higher termination rate reported recently by a single large U.S. referral center suggests that regional differences in counseling may also be important. In over $20 \%$ of our cases, the diagnosis of SV was made beyond 24 weeks of gestation, emphasizing the importance of skilled recognition of potential cardiac defects on screening ultrasounds and the need for prompt fetal cardiology referral when any cardiac problem is suspected.
\end{abstract}

\section{Introduction}

Hypoplastic Left Heart Syndrome (HLHS) accounts for 7-8\% of all congenital heart disease, and it is one of the most common defects diagnosed prenatally [1,2]. Before the 1980's, this diagnosis was uniformly fatal, usually in the first week of life [3]. In most centers, parents were informed of this when a fetal diagnosis of HLHS was made and after birth only palliative care was provided. Over the last 3 decades, an effective but high-risk surgical approach, staged palliation beginning with a Norwood procedure shortly after birth, has become the standard management of HLHS and other functional Single Ventricle (SV) diagnoses. Outcomes and survival rates have steadily improved, so prenatal diagnosis now includes specific counseling about this option. However, even with prenatal diagnosis, planning, and a high level of intention to treat, HLHS accounts for up to $25 \%$ of all cardiac deaths in the first week of life. Other forms of functional single ventricle defects are less common, but their prognosis with staged palliation is comparable. Additionally, the long-term prognosis for children and young adults remains uncertain and thus, prenatal termination and palliative care after birth are also described to parents as options $[4,5]$.

Despite the evolving prognosis and informed counseling, rates of pregnancy termination for severe congenital heart disease including
HLHS in North America have been consistently reported to be between $12-25 \%$ over the past 20 years, much lower than rates in Europe, Asia, and Australia [2,5-17] (Table 1). A single U.S. study of SV cases diagnosed between 1995 and 2008 recently reported a higher overall termination rate of $31 \%, 49 \%$ when the diagnosis was made before 24 weeks of gestation $[18,19]$. With improved outcomes and survival with neonatal palliation and conflicting reports of termination rates, an updated analysis of contemporary pregnancy outcomes in the current era is needed as the most recent series extended only to 2009.

Besides prenatal counseling, several other factors including cultural, religious, and socio-economic factors contribute to parental decisions to terminate $[11,20]$. To date, there is limited data assessing

Correspondence to: Katie Mowers, MD Saint Louis Children's Hospital Washington University School of Medicine, Saint Louis, USA, Tel: (231) 6700006, (314) 424-4533, Fax: (314) 424-2561; Email: Mowers_K@kids.wustl.edu

Key words: hypoplastic left heart syndrome, single ventricle, fetal echocardiographic diagnosis, pregnancy termination

Received: March 01, 2017; Accepted: March 22, 2017; Published: March 25 2017 
Table 1. Comparison of published termination rates

\begin{tabular}{|c|c|c|c|c|c|}
\hline Investigator & $\begin{array}{l}\text { Report } \\
\text { Year }\end{array}$ & Country & Study Design & $\begin{array}{c}\text { Date of fetal diagnosis of } \\
\text { HLHS/severe CHD }\end{array}$ & $\begin{array}{l}\text { Rate of pregnancy } \\
\text { termination }\end{array}$ \\
\hline Beroukhim et al.,[18] & 2015 & USA & Retrospective & $1995-2008$ & $98 / 312(31 \%)^{*}$ \\
\hline Noseda et al.,[17] & 2012 & France & Retrospective & $2006-2010$ & $9 / 16(56 \%)$ \\
\hline Axt-Fliedner et al.,[16] & 2012 & Germany & Retrospective & $1994-2011$ & $17 / 105(16 \%)$ \\
\hline Rychik et al.,[5] & 2010 & USA & Retrospective & 2004-2009 & $38 / 240(15.8 \%)$ \\
\hline Lee et al.,[15] & 2010 & Korea & Retrospective & $1994-2005$ & $68 / 336(20.2 \%)$ \\
\hline Galindo et al.,[14] & 2009 & Spain & Retrospective & $1998-2006$ & $58 / 73(79 \%)$ \\
\hline Rasiah et al.,[1] & 2008 & UK & Retrospective & $2000-2004$ & $20 / 79(25.3 \%)$ \\
\hline Hsiao et al.,[13] & 2007 & Taiwan & Retrospective & $1995-2000$ & $30 / 106(29.1 \%)$ \\
\hline Zhu et al.,[12] & 2006 & China & Retrospective & $2003-2004$ & $24 / 43(52 \%)$ \\
\hline Allen et al.,[9] & 2005 & USA & Retrospective & $1992-2003$ & $32 / 176(18.7 \%)$ \\
\hline Menaham et al.,[11] & 2003 & Australia & Prospective & $2000-2003$ & $13 / 40(32.5 \%)$ \\
\hline Verheijen et al.,[2] & 2003 & Netherlands & Retrospective & $1988-2001$ & $16 / 32(50 \%)$ \\
\hline Tworetzky et al.,[8] & 2001 & USA & Retrospective & 1992-1999 & $11 / 88(12.5 \%)$ \\
\hline Brackley et al.,[10] & 2000 & UK & Retrospective & 1994-1999 & $38 / 87(44 \%)$ \\
\hline Munn et al.,[7] & 1999 & USA & Retrospective & 1991-1996 & $3 / 15(20 \%)$ \\
\hline Allan et al.,[6] & 1998 & USA & Retrospective & $1993-1996$ & $4 / 12(25 \%)$ \\
\hline
\end{tabular}

"Pregnancy termination rate reported at $49 \%$ when FE diagnosis was made before 24 weeks.

longitudinal trends in pregnancy termination rate, particularly with significant provider and counseling consistency. This information is important as parents need to be optimally informed about the potential outcome of any fetal cardiac diagnosis.

\section{Methods}

The URMC fetal echocardiogram database was retrospectively searched from the beginning of routine fetal echocardiography in May 1996 through January 2013. All fetal ultrasounds were interpreted by the same pediatric cardiologist who performed all of the prenatal counseling. Information provided reflected the contemporary status of short- and midterm outcomes after palliative surgery. All fetuses found to have a prenatal diagnosis of HLHS or other functional single ventricle defect requiring staged palliation beginning with a Norwood reconstruction were included. Minor variants of HLHS suitable for biventricular repair were excluded.

A review of the medical record was performed to identify information regarding maternal history (age, gravity, and parity), sonographic findings/diagnosis, gestational age at diagnosis, results of karyotype testing, extra-cardiac anomalies, number of prenatal visits with pediatric cardiologist, as well as pregnancy outcome. Patients were categorized into one of two categories: high-risk or standardrisk. High-risk was defined as the presence of extra-cardiac, genetic, or chromosomal anomalies; or, additional cardiac findings such as intact or highly restrictive atrial septum, severe degree of tricuspid regurgitation, or severe ventricular dysfunction. Standard-risk was defined as the absence of these risk factors. Review of the medical literature for fetal ultrasound and HLHS/ single ventricle was performed to provide historic comparison of pregnancy termination rates. Chisquared analysis or Fisher's exact test was used to assess differences in maternal demographic, diagnoses, and pregnancy outcomes between high-risk and standard-risk fetuses. Fisher's exact test was used to compare termination rates in international and American centers. $\mathrm{P}$ $<0.05$ was considered statistically significant.

\section{Results}

Over 17 years, 2411 fetal echocardiograms were performed with 149 single ventricle diagnoses $(0.062 \%)$. In 31 cases $(17 \%)$, the FE diagnosis was made at $>24$ weeks gestation and these cases are excluded from the analysis. Initial fetal echocardiography and counseling by the fetal cardiologist were performed at a mean of $21 \pm 3.2$ weeks' gestation. Mean maternal age at diagnosis was $30 \pm 5.6$ years. This was the first pregnancy for $26 \%$ of the mothers, and $78 \%$ were married. Specific diagnoses included 56 (48\%) HLHS, 25 (21\%) hypoplastic right heart, 23 (19\%) complex SV, 14 (12\%) unbalanced AV septal defect. Eightyone fetuses (69\%) were standard risk and 37 (31\%) were high risk. Of the high-risk fetuses, 27 (73\%) had a major extracardiac, genetic, or chromosomal anomaly (Table 2$), 7$ (19\%) had an intact or severely restrictive atrial septum, and $3(8 \%)$ had additional cardiac risk factors (severe AV valve regurgitation or severe ventricular dysfunction).

Overall termination rate was $15.4 \%$, with 95\% CI (11.67\%-20.53\%). Termination rates varied from year to year throughout the review period but there was no significant trend over time (Figure 1). There was no statistically significant difference in maternal demographics (age, marital status, history of previous pregnancy, ethnicity, gender, gestational age at diagnosis) between continued pregnancies and those which were terminated (Table 3 ). Of terminated pregnancies, 10 (53\%) were diagnosed with HLHS, 5 (26\%) with HRHS, 3 (16\%) with complex single ventricles, and 1 (5\%) with an unbalanced AV septal defect (Figure 2). We found no significant difference in proportion of families who chose pregnancy termination between the high-risk and standard-risk groups (Figure 3).

Published pregnancy termination rates from all identified reports of fetal diagnosis of HLHS/SV are displayed in Table 1. Reports include FE diagnoses made between 1995 and 2009. Ten reports were from international centers and 6 were from American centers. All but one [11] were retrospective single center reports. Termination rates ranged from 16 to $79 \%($ mean $=32 \%)$ in reports from international centers and from 12.5 to $31 \%$ (mean $=18.4 \%)$ in American centers $(p=0.00003)$. No previous study reported trends in termination rates over time.

\section{Discussion}

Despite improvements in surgical outcomes and counseling consistency provided by a single pediatric cardiologist, we found no significant trend in pregnancy termination rates over the past 17 years after prenatal diagnosis of SV heart defects. Over this time period as awareness has increased, more SV diagnoses are made at an earlier gestational age, and surgical outcomes have improved, changes in pregnancy termination rates would be anticipated; however, we did not 


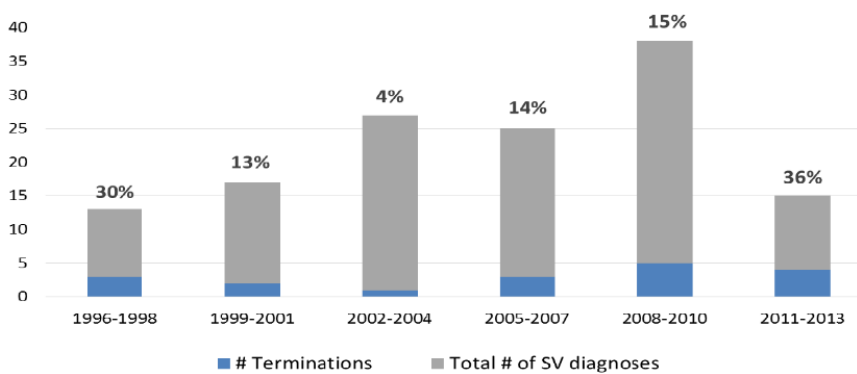

Figure 1. Pregnancy termination rates over time

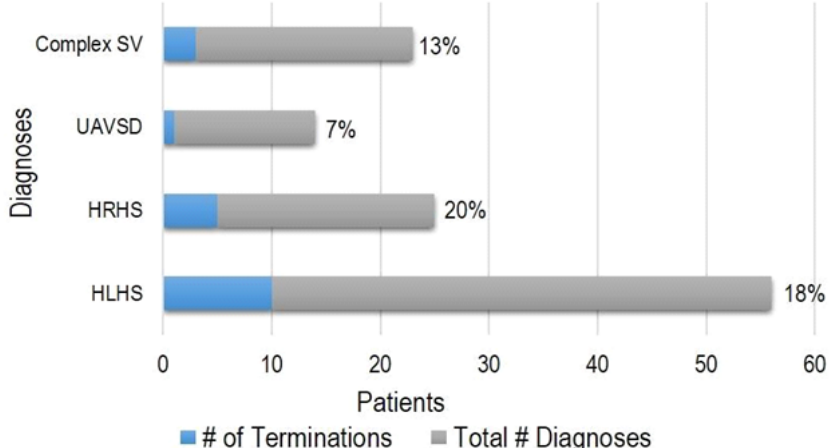

Figure 2. Pregnancy termination rates by diagnosis

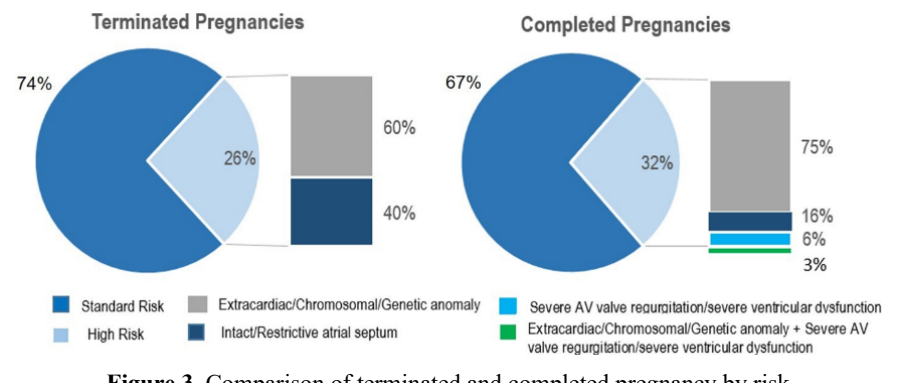

Figure 3. Comparison of terminated and completed pregnancy by risk.

find this to be the case. Previous studies have reported differences in early outcomes between fetuses stratified into high-risk and standardrisk groups [5], and one might also expect to see a higher proportion of families choosing pregnancy termination in the high-risk group. However, as in previous reports, we found no significant difference in the pregnancy termination rate between the high and standard-risk groups. These findings suggest that factors other than cardiac prognosis are the major determinants in family decision-making after a fetal diagnosis of single ventricle. Other factors including cultural, religious, and socio-economic factors are known to be important determinants of parental decision making when considering pregnancy termination.

Additionally, 21\% (31/149) of patients were diagnosed after 24 weeks' gestation, beyond the legal limit for termination in New York State, and the mean fetal age at diagnosis for the remainder was 21 weeks. This emphasizes the importance of recognition of potential cardiac defects on screening ultrasounds and the need for prompt referral to a pediatric cardiologist for diagnosis as soon as any cardiac problem is suspected. Review of the medical literature indicates that the termination rates in this review are similar to those reported for American centers since 1998, consistently and significantly lower than those from international centers with the exception of a single recent report from the Boston Children's Hospital [18]. The discrepancy between our contemporary series and the 1995-2008 series from Boston suggests regional differences in approach to prenatal counseling may additionally impact parental decision making.

Our study has several limitations. Information regarding cultural, religious, and socio-economic status of parents was not consistently documented and thus it was not possible to include this in our analysis. Prenatal risk factors such as genetic anomalies may also be underestimated as not all fetuses underwent amniocentesis. It is also possible that our termination rates are underestimated, as in some cases the diagnosis of SV was made at an outside institution and thus initial prenatal counseling was not performed in our fetal medicine program. In these situations, families already interested in surgical palliation may have been preferentially referred for evaluation, while those interested in pregnancy termination may not have been referred at all.

Our findings agree with those from most other American centers over the last 20 years and suggest that termination rates after fetal diagnosis of HLHS/single ventricle have not been significantly affected by progress in surgical palliation. The results suggest that

Table 2. Extracardiac, genetic, and chromosomal anomalies in the high-risk group

\begin{tabular}{|c|c|}
\hline Anomaly & Number of fetuses affected \\
\hline Renal anomaly & 4 \\
\hline Heterotaxy syndrome & 4 \\
\hline Brain anomaly & 4 \\
\hline Skeletal anomaly & 2 \\
\hline Omphalocele & 2 \\
\hline Congenital cystic adenomatoid malformation & 1 \\
\hline Congenital Diaphragmatic Hernia & 1 \\
\hline Pentology of Cantrell & 1 \\
\hline Severe non-specific dysmorphism & 1 \\
\hline Trisomy 21 Genetic/Chromosomal \\
\hline Trisomy 18 & 4 \\
\hline Trisomy 13 & 4 \\
\hline
\end{tabular}

Table 3. Demographic data

\begin{tabular}{|c|c|c|c|}
\hline & $\begin{array}{l}\text { Terminations } \\
\qquad(\mathrm{n}=19)\end{array}$ & $\begin{array}{l}\text { Continued } \\
\text { Pregnancies } \\
\quad(n=99)\end{array}$ & $\begin{array}{c}\text { X2 or Fisher's } \\
\text { Exact Test }\end{array}$ \\
\hline Maternal Age in years, mean (+/- SD) & $31.32+/-4.91$ & $29.68+/-6.29$ & $\mathrm{p}=0.2856$ \\
\hline $\begin{array}{l}\text { Gestational age at diagnosis in } \\
\text { weeks, mean (+/-SD) }\end{array}$ & $20.58+/-1.71$ & $21.16+/-2.39$ & $\mathrm{p}=0.3133$ \\
\hline History of previous pregnancy, $\mathrm{n}(\%)$ & & & $\mathrm{p}=0.3926$ \\
\hline History of previous pregnancy, $\mathrm{n}(\%)$ & $14(74 \%)$ & $68(69 \%)$ & \\
\hline First pregnancy, n (\%) & $3(16 \%)$ & $28(28 \%)$ & \\
\hline Unknown, n (\%) & $2(10 \%)$ & $3(3 \%)$ & \\
\hline Marital status & & & $\mathrm{p}=0.3578$ \\
\hline Married, n (\%) & $17(95 \%)$ & $75(76 \%)$ & \\
\hline Single, n (\%) & $2(5 \%)$ & $23(23 \%)$ & \\
\hline Unknown, n (\%) & - & $1(1 \%)$ & \\
\hline Ethnicity & & & $\mathrm{p}=0.6757$ \\
\hline White/Non-Hispanic, n (\%) & $14(73 \%)$ & $73(74 \%)$ & \\
\hline White/Hispanic, n (\%) & $2(11 \%)$ & $8(8 \%)$ & \\
\hline Black/African American, n (\%) & $2(11 \%)$ & $15(15 \%)$ & \\
\hline Asian American, n (\%) & $1(5 \%)$ & $2(2 \%)$ & \\
\hline Unknown, n (\%) & - & $1(1 \%)$ & \\
\hline Gender & & & $\mathrm{p}=0.7258$ \\
\hline Male, n (\%) & $8(42 \%)$ & $49(50 \%)$ & \\
\hline Female, n (\%) & $6(32 \%)$ & $45(45 \%)$ & \\
\hline Unknown, n (\%) & $5(26 \%)$ & $5(5 \%)$ & \\
\hline
\end{tabular}


family decision making after prenatal diagnosis of single ventricle is not primarily influenced by cardiac prognosis. In order to completely assess pregnancy termination rates, future studies are needed to confirm our findings and to assess all the medical, religious, cultural, and socioeconomic factors that potentially influence parental decision making. While many other factors likely contribute to this difficult parental decision, it remains imperative to provide families with accurate and timely prognostic information in order to optimally support them during this process.

\section{Conclusion}

Our review provides an updated analysis of pregnancy termination rates after fetal ultrasound diagnosis of HLHS/SV in an era with improved outcomes and decreased surgical mortality. Over a 17year period in our center, termination rates in pregnancies with $\mathrm{FE}$ diagnosis of SV were low, consistent with reports from American centers dating back to 1998 with no significant trend over time. This lack of change suggests that factors other than cardiac prognosis are major determinants in family decision-making after a fetal diagnosis of SV. We report a significantly lower termination rate than the other contemporary American review, suggesting regional differences in counseling may also affect parental decision making. Additionally, in over $20 \%$ of cases, the diagnosis of SV was made beyond 24 weeks of gestation, emphasizing the importance of skilled recognition of potential cardiac defects on screening ultrasounds and the need for prompt fetal cardiology referral when any cardiac problem is suspected.

\section{References}

1. Rasiah SV, Ewer AK, Miller P, Wright JG, Barron DJ, et al. (2008). Antenatal perspective of hypoplastic left heart syndrome: 5 years on. Arch Dis Child Fetal Neonatal 93: F192-197. [Crossref]

2. Verheijen PM, Lisowski LA, Plantinga RF, Hitchcock JF, Bennink GB, et al. (2003) Prenatal diagnosis of the fetus with hypoplastic left heart syndrome: management and outcome. Herz 28: 250-256. [Crossref]

3. [No authors listed] (1980) Report of the New England Regional Infant Cardiac Program. Pediatrics 65: 375-461. [Crossref]

4. Allan LD1, Sharland G, Tynan MJ (1989) The natural history of the hypoplastic left heart syndrome. Int $J$ Cardiol 25: 341-343. [Crossref]

5. Rychik J, Szwast A, Natarajan S, Quartermain M, Donaghue DD, et al. (2010) Prenatal and early surgical outcome for the fetus with hypoplastic left heart syndrome: a 5-year single institutional experience. Ultrasound Obstet Gynecol 36: 465-470. [Crossref]
6. Allan LD1, Apfel HD, Printz BF (1998) Outcome after prenatal diagnosis of the hypoplastic left heart syndrome. Heart 79: 371-373. [Crossref]

7. Munn MB, Brumfield CG, Lau Y, Colvin EV (1999) Prenatally diagnosed hypoplastic left heart syndrome-outcomes after postnatal surgery. J Matern Fetal Med 8: 147-150. [Crossref]

8. Tworetzky W, McElhinney DB, Reddy VM, Brook MM, Hanley FL, et al. (2001) Improved surgical outcome after fetal diagnosis of hypoplastic left heart syndrome. Circulation 103: 1269-1273. [Crossref]

9. Allen RH, Benson CB, Haug LW (2005) Pregnancy outcome of fetuses with a diagnosis of hypoplastic left ventricle on prenatal sonography. J Ultrasound Med 24: 1199-1203. [Crossref]

10. Brackley KJ, Kilby MD, Wright JG, Brawn WJ, Sethia B, et al. (2000) Outcome after prenatal diagnosis of hypoplastic left-heart syndrome: a case series. Lancet 356: 11431147. [Crossref]

11. Menahem S, Grimwade J (2003) Pregnancy termination following prenatal diagnosis of serious heart disease in the fetus. Early Hum Dev 73: 71-78. [Crossref]

12. Zhu RY, Gui YH, Li LC, Sun L, Chang C (2006) Fetal echocardiography in diagnosing congenital heart disease prenatally: a multicenter clinical study. Zhonghua Er Ke Za Zhi 44: 764-769. [Crossref]

13. Hsiao SM, Wu MH, Jou HJ, Lee CN, Shyu MK, et al. (2007) Outcome for fetuses with prenatally detected congenital heart disease and cardiac arrhythmias in Taiwan. $J$ Formos Med Assoc 106: 423-431. [Crossref]

14. Galindo A, Nieto O, Villagra S, Graneras A, Herraiz I, et al. (2009) Hypoplastic left heart syndrome diagnosed in fetal life: associated findings, pregnancy outcome and results of palliative surgery. Ultrasound Obstet Gynecol 33: 560-566. [Crossref]

15. Lee JE, Jung KL, Kim SE, Nam SH, Choi SJ, et al. (2010) Prenatal diagnosis of congenital heart disease: trends in pregnancy termination rate, and perinatal and 1-year infant mortalities in Korea between 1994 and 2005. J Obstet Gynaecol Res 36: 474478. [Crossref]

16. Axt-Fliedner R1, Enzensberger C, Fass N, Vogel M, Kawecki A, et al. (2012) Fetal diagnosis of hypoplastic left heart, associations and outcomes in the current era. Ultraschall Med 33: E51-56. [Crossref]

17. Noseda C, Mialet-Marty T, Basquin A, Letoumeur I, Bertorello I, et al. (2012) Severe Hypoplastic left heart syndrome: palliative care after prenatal diagnosis. Arch Pediatr 19: 374-380. [Crossref]

18. Beroukhim RS, Gauvreau K, Benavidez OJ, Baird CW, LaFranchi T et al. (2015) Perinatal outcome after prenatal diagnosis of single-ventricle cardiac defects. Ultrasound Obstet Gynecol 45: 657-663. [Crossref]

19. Ohye RG, Sleeper LA, Mahony L, Newburger JW, Pearson GD, et al. (2010) Comparison of shunt types in the Norwood procedure for single-ventricle lesions. $N$ Engl J Med 362: 1980-1992. [Crossref]

20. Tarabit K, Bui TTT, Lelong N, Thieulin AC, Goffinet F, et al. (2013) Clinical and socioeconomic predictors of pregnancy termination for fetuses with congenital heart defects: a population-based evaluation. Prenatal Diagnosis 33: 179-186. [Crossref]

Copyright: (C2017 Mowers KL. This is an open-access article distributed under the terms of the Creative Commons Attribution License, which permits unrestricted use, distribution, and reproduction in any medium, provided the original author and source are credited. 